2014

\title{
The Discursive Construction and Performance of Gendered Identity on Social Media
}

Julia Cook, University of Melbourne

Reza Hasmath, University of Oxford 


\title{
The discursive construction and performance of gendered identity on social media
}

\section{Julia Cook}

University of Melbourne, Australia

\section{Reza Hasmath}

University of Oxford, UK

\begin{abstract}
This article looks at the construction and performance of gendered identity through a sub-section of Facebook web pages belonging to the Slut Walk movement. The authors' analysis suggests that gender is constructed through the subjects' participation in the 'post-feminist masquerade' through which their gendered identity is defined in relation to a hegemonic masculine ideal. This situates the web pages within a space characterized through the ambivalent and appropriative treatment of feminism and further, coiled within an acute tension between feminist and post-feminist discourses. Acts of resistance are framed as individual, momentary ruptures of Judith Butler's heterosexual matrix of 'cultural intelligibility'. The online context of these ruptures is found to vest a creative potential, by removing the constraints of time and location, indicating that the impact of these ruptures may extend beyond its immediate environment.
\end{abstract}

\section{Keywords}

Facebook, feminism, gender identity, resistance, Slut Walk, social media

\section{Introduction}

The Slut Walk movement began as a protest in Toronto, Canada, on 3 April 2011, in response to a Toronto Police Service officer's advice to students that 'women should avoid dressing like sluts in order to not be victimized' (Savage, 2011). It subsequently

\section{Corresponding author:}

Reza Hasmath, University of Oxford, Dickson Poon Building, Canterbury Road, Oxford OX2 6LU, UK.

Email: rhasmath@gmail.com 
evolved into a worldwide series of marches and rallies protesting against the blame assigned to victims of sexual assault. Although these marches and rallies were mobilized independently in each locale, in many cases they had been organized and coordinated through web pages on Facebook.

Although the Facebook web pages initially provided spaces for the founders of the sites to convey information about upcoming marches and rallies to interested parties, these pages have also become spaces for engagement with the central aims of the movement: the reclamation and reappropriation of discourses concerning expressions of gender and sexuality, and the vaguely stated aim of 'inclusiveness'. Since these pages are a space in which individuals can engage with and discuss the broader aims of the movement, and further, because they connect some of the disparate locales which participated in this movement, they provide a useful platform to analyse the ability of this movement to meet its own aims.

In this vein, this article explores the subversive potential afforded to subjects by their engagement with the online manifestation of the Slut Walk movement found on a subsection of Facebook web pages. We question how gendered identities are constructed and performed on these sites. Do subjects have the potential to resist these constructions? Further, what impact does the online environment have on these findings? By addressing these questions we aim to determine the extent to which subjects are able to reclaim and reappropriate discourse and therefore meet the stated aims of the Slut Walk movement in their engagement with these web pages.

\section{Theoretical framework}

\section{Third-wave feminism and 'post-feminism'}

The Slut Walk movement's aim of reclaiming and reappropriating discourse is directly implicated in its treatment of feminism, which plays out some of the tensions rife within contemporary discourses of feminism. Specifically, the movement is marked by the competing and yet overlapping discourses of third-wave feminism and 'post-feminism'.

Third-wave feminism, which emerged during the early 1990s, critically engages with the feminist sex wars of the 1970s and 1980s which, for third-wave feminists, have largely been distilled into a conflict between protecting or liberating women in the face of practices which are perceived to be oppressive, such as pornography (Butler, 2013). Importantly, third-wave feminism is presented as a progressive corrective to earlier visions of feminism because: first, it has been directly implicated in the development of intersectional approaches which aim to identify how gender intersects with other facets of a subject's identities (Crenshaw, 1994); and second, it has adopted a 'sex-positive' and liberatory approach in order to differentiate itself from the perceived negativity of earlier iterations of feminism, with the intention of bringing young women back to feminism.

While third-wave feminism actively engages with earlier forms of feminism, 'postfeminism' strives to replace feminism altogether. Although 'post-feminism' is a notoriously ambiguous concept, it has been broadly characterized by the ambivalent relationship which it has with feminism. It accepts and celebrates the achievements of feminism whilst positing that these achievements render it unnecessary (McRobbie, 2009). Importantly, 
'post-feminism' is inherently implicated in a neoliberal context which cultivates a form of subjectivity that requires subjects to become increasingly self-governing and self-reliant. ${ }^{2}$ 'Post-feminism' and neoliberalism are united by the mutual development of rhetorics of personal responsibility and individual choice.

In this study we focus on the question of how discourses of feminism and 'post-feminism' have impacted upon the ability of the online manifestations of the Slut Walk movement to meet its stated aims.

\section{Gender as performatively constructed}

Judith Butler's conceptualization of gender as performatively constructed is used as an operating lens in our investigation of identity construction and resistance. Butler (1990: 34) argues that there is no pre-discursive subject, and through this defines gender as a process. This releases gender from the binary understanding of sex as biological and gender as socially assigned that has predominated within the academy. Instead she views both gender and sex as produced within the heterosexual matrix. Butler (1990: 23-24) conceptualizes the heterosexual matrix as having the ability to render subjects culturally intelligible (that is, as able to be read discursively) by generating ideal relationships between sex, gender and desire, held in place and reinforced by norms of 'bodily gestures, practices, declarations, actions and movements' (Lloyd, 2007: 48).

The central role that language and discourse plays in this study positions declarations as the focal point of examination. Within this framework resistance to dominant constructions of gendered identity is therefore understood as resistance to the heteronormative relationship constructed within the heterosexual matrix. Butler herself points to a potential space for resistance: the inherently unstable nature of the heterosexual matrix illustrated by the necessity for subjects to constantly repeat the norms that solidify it. This process of repetition illustrates that such norms are not fixed, and instead must be constantly stabilized, which vests subjects with the potential to repeat norms in a different manner, and enact a process through which these norms can be subverted.

Butler (1990: 188) identifies 'parodic styles' as the type of subversive repetition capable of throwing the perceived naturalness of heterosexuality into question. This is achieved by subjects through denaturalization of the norms that solidify the heterosexual matrix, which makes evident their nature as performative constructions. The aim of Butler's subversive politics is the creation of a space in which non-normative genders, sexualities and sexes may achieve legitimacy (Lloyd, 2007: 57). The potential for such resistance is located in the spaces that emerge within the heterosexual matrix through parody of the norms that construct and solidify it. Butler's subversive gender politics are central to this study, for which they are used as a template to identify whether subversions of dominant constructions of gender are enacted within a network of web pages, and whether these subversions, in the words of Butler (2006: 533), constitute a 'strike or blow' against the heterosexual matrix. Moreover, engagement with Butler's subversive gender politics facilitates an understanding of the means that individual subjects have to resist the way in which they are constructed. As this study focuses on a collective movement, it is necessary to question whether the subversive potential afforded to subjects by 
the use of computer-mediated communication (CMC) can be extended to provide an account of intersubjective resistance.

Angela McRobbie (2009) extends Butler's conceptualization of a 'double entanglement', relating it to the contemporary treatment of feminism as taken to be common sense while simultaneously reviled. Although McRobbie investigates 'luminous' spaces of attention and in the process, structuring the norms holding Butler's heterosexual matrix in place, only the 'post-feminist masquerade' is utilized within this study. The 'post-feminist masquerade' refers to a style that may be adopted by women 'to help [them] navigate the terrain of hegemonic masculinity without jeopardising [their] sexual identity' aiding their navigation of undesirable subject positions (McRobbie, 2009: 67). McRobbie's work is useful as it facilitates an understanding of the specific discourses (working as norms) that construct subject's identities. Relatedly, Maria Bakardjieva's (2008) study of online forums as carnival is somewhat sympathetic with McRobbie's work, as it provides an illustration of how such ideas can be converted into an online context by emphasizing the navigation of a political landscape through hyperbolic performances of the self which are facilitated by the unique nature of the online spaces (such as a degree of anonymity).

\section{The online context}

Since their advent in the late 1990s, social network sites (SNSs) have been harnessed by users as a platform to construct and perform gendered identities (boyd and Ellison, 2008). This is evident when examining the conclusions of early studies of gender differences in online communication, looking at asynchronous (i.e. interaction taking place over varying amounts of time) and synchronous (i.e. real-time interaction) online environments. While studies of asynchronous online environments suggested that the presentation of gendered identities largely mirrored its presentation in a face-to-face (FTF) context (Herring, 1993; Selfe and Meyer, 1991), findings looking at synchronous online environments challenged this viewpoint (Danet, 1998; Rodino, 1997). ${ }^{3}$ Such studies illustrated the potential that $\mathrm{CMC}$ has to reflect and reinforce gender relations observed in FTF interaction, and facilitate performances of gender that contest a binary understanding.

The subversive potential identified within a subject's engagement with CMC was examined by scholarship investigating the role played by language and discourse in the construction and performance of gendered identities online, exploring the liberatory potential of the disembodied characteristic of an online environment (Bornstein, 1998; Reid, 1993). Although this work can be critiqued for presenting a binaristic account of the relationship between online and offline environments, it nevertheless illustrates the capacity that an elective process of identity construction has to challenge dominant understandings of gender, and highlights a subject's use of language and discourse as a key site through which such creative capacity can be accessed.

Scholarship exploring the subversive potential provided by CMC has been expanded by studies making use of Judith Butler's concept of the 'heterosexual matrix'. While the foundation of this scholarship was laid by Bechar-Israeli's (1995) study of the opportunities which nicknames afforded users of Internet Relay Chat for establishing a playful and 
fluid identity, and Rodino's (1997) engagement with Butler's work, recent studies have been implicated in 'post-feminist' discourses (McRobbie, 2009). This complicates a subject's negotiation of identity construction and performance by reframing this process as a navigation of undesirable subject positions, characterized by hyper-sexualization on the one hand, and a complete divorce from sexuality on the other. Renold and Ringrose $(2008,2012)$ have used such work to explore the subversive potential provided to subjects by their use of CMC to resist dominant constructions of gender - that is, located in the potential for resistance in small-scale, individual ruptures of the heterosexual matrix rather than large-scale acts of resistance. Subsequent studies expanded upon this finding, focusing on how the freedom of the fluid environment of SNSs helped subjects to enact these moments of resistance and subversion (Kofoed and Ringrose, 2012; Ringrose and Barajas, 2011).

Such work is again constrained by its limitation to online spaces. It is therefore useful to turn to recent scholarship highlighting the way in which the creative capacity of language and discourse can be disembedded from its online context. By exploring the use of smart phones to facilitate mass mobilization throughout the 'Occupy' movement (Jurgenson, 2012), and the use of Facebook for political mobilization during the 2008 US federal election (Vitak et al., 2011), such studies have endeavoured to break down a binary understanding of online and offline environments in favour of a fluid conceptualization of their relationship. This work has important implications for this study as it attempts to resist dominant gender constructions, further suggesting that the impact of such acts could potentially be extended beyond their immediate online context.

Although the theoretical approaches outlined above provide a framework through which to explore processes of identity construction, it is necessary to interrogate the impact of an online context upon these processes without presenting an essentialist view of such spaces. The data collected from the relevant Facebook web pages for this study can be labelled as socio-technical systems, a term proposed by Niederer and Van Dijck (2010) to refer to online spaces which are formed through both social and technological components. By contextualizing the development of social media platforms (specifically Twitter $)^{4}$ within a long line of communication technologies, Murthy (2012) emphasizes the qualitatively new elements of these spaces while avoiding essentialist tendencies. Notably, using Erving Goffman's (1959) symbolic interactionism as a starting point he explores subjects' 'embedding capacity'; that is, their ability to embed utterances which did not originate with them within new contexts. By illustrating how tweets (textual messages) on Twitter can be appropriated by other users and circulated beyond their anticipated context, Murthy highlights an online manifestation of this concept. Based upon the way in which tweets can be re-embedded within new contexts Murthy terms this 'synthetic embedding', a concept which dismisses the need for a situated present and therefore constitutes a departure from Goffman's work. The parallels between the highlighted features of Twitter and the Facebook web pages analysed in this study illustrate the applicability of Murthy's approach to this work. Such an approach allows analysis to be extended to exploration of the relevance of the online context of the sites since it is able to contend with new facets of online spaces: their informational nature, ontological fluidity, and their ability to act as a proxy for a third party in asynchronous communication (Knorr Cetina, 2009: 69). 


\section{Methodology}

The study focuses on a sub-section of Facebook web pages, each of which were the online manifestation of the Slut Walk movement in a locale around the world. Although this movement was discussed on a number of online forums, including other social media platforms, we focused on Facebook as an initial review illustrated that the pages on this platform witnessed the most active and sustained discussion of the movement and its aims.

The data collection process took place from June to July 2012. Since the Slut Walk presence on Facebook is comprised of over 100 local groups it was necessary to limit the sample - this was achieved through the use of a snowball sampling technique to collect the data. We initially started by looking at the first Slut Walk Facebook group (Toronto) and moved chronologically to other local Slut Walk Facebook groups. The data were collected from content posted to the 'Wall' on each page by the administrators (who established and moderated the page), ${ }^{5}$ and commenters/collaborators (who interacted with the content by contributing posts and commenting on existing posts). ${ }^{6}$ This process continued until we achieved data saturation. In the end, the Wall posting of 13 local Slut Walk Facebook groups, with an average of 105 posts (by mediators) and 496 comments (from contributors) for each Wall, was analysed.

The site administrators were primarily responsible for the distribution of key information about the marches, and stimulating discussion about the objectives of the movement by posting relevant content on the web pages. Strictly speaking the administrators partially influenced the discussions that the commenters engaged in. Although practically, the administrators generally used their role to ensure that the commenters remain focused on the key tenets and issues of the movement.

Quantifying the exact size of the Slut Walk movement was challenging due to the fact the Facebook pages are publicly accessible, and as such, individuals can glance at the pages without recording their presence. Given page traffic data were not accessible, the total number of discrete contributors were recorded for each page (see Table 1) and used as a proxy for estimating activity. When compared with the Facebook pages of other social movements, for instance, the Occupy movement, the Slut Walk movement has a comparable number of posts, and interestingly, has a larger base of discrete commenters/ collaborators. ${ }^{7}$

We established commonality across the network of Facebook groups through the collection of demographic information from collaborators, and comparison of discourses on each web page which were found to have a high degree of similarity. ${ }^{8}$ Although discourses - rather than discrete web pages - formed the focal point of the study's analysis, the data were not de-identified from their locale during the analysis due to the importance of examining similarities and differences between the web pages. Although the Slut Walk movement spread around the globe, the web pages - which were interconnected with the Facebook page representing the original movement in Toronto - generally represented locales which had some key commonalities. Most notably, the web pages were overwhelmingly from developed nations which shared a 'globalized culture'. This is not to discount the relevance of culturally specific experiences. Rather, it is intended to highlight that the online connections which were forged between them were premised on important similarities. 


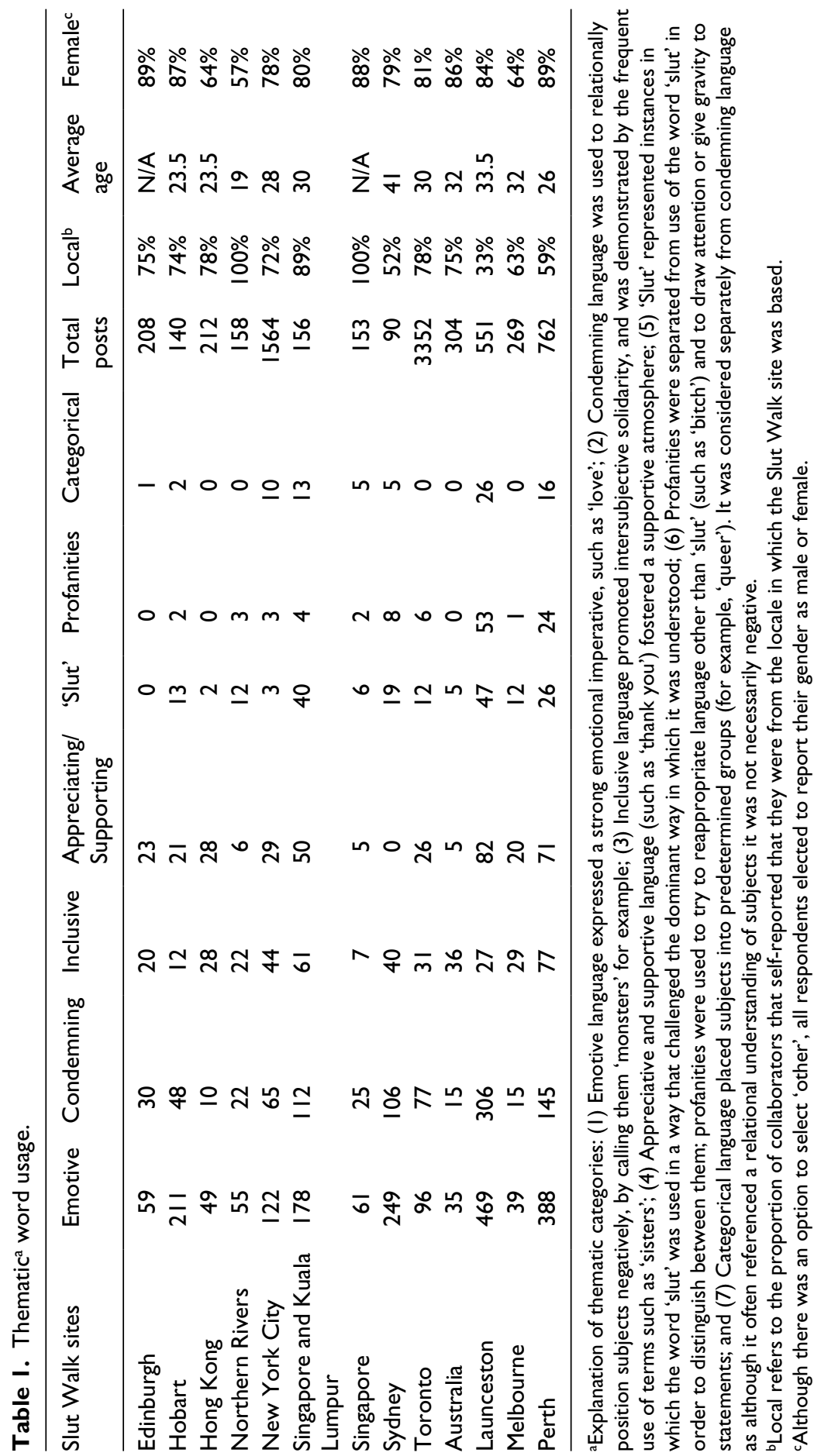


Data were studied using a critical discourse analysis informed by the work of Norman Fairclough (2003). This approach accommodated the importance of language and discourse within this research, allowing data to be considered at three levels: textual analysis - focusing on micro-linguistic concerns; discursive practice - concerned with a mesoanalysis of the way in which texts were socially produced; and social practice - engaging with a macro-analysis and allowing for contextualization of the text within a wider context. The applicability of these categories was confirmed by a pilot study of a single site. Data were then organized thematically to allow the questions motivating this research to be addressed.

The data collected from the network of sites were produced collaboratively and therefore necessitated the adoption of a fluid, non-linear approach to analysis in which the diverse voices within it could be placed in dialogue. This consideration informed the inductive approach taken to data analysis, allowing a sense of context to be achieved before the data were coded thematically (Hine, 2000). This process began with an examination of how discourses were deployed to construct meaning. The data were then reorganized thematically to allow the diverse voices to be examined in order to establish the discourses that were dominant. Close linkages were ensured between each stage of analysis in order to preserve the context of the original data, aiming to produce research that was representative of its original environment.

Although it is uncommon to include the demographic details of the samples used in studies of online spaces, we have included information on the age and gender of the contributors where possible, first, to strengthen the argument that the degree of commonality between the web pages was sufficient for their combined analysis, and second, due to the strong focus which this piece has on the way in which various expressions of identity intersect with gender. This approach has been used successfully in early studies of the presentation of self in online contexts (see Rodino, 1997).

The parameters of research were constrained by the impossibility of accessing demographic information for all of the individuals that contributed to these sites and impacted by the elective and self-reported nature of demographic information on Facebook. Demographic information was missing from the pages of some individuals, resulting in incomplete information in our sample. Furthermore, demographic information that was reported could not be verified, meaning that it was not feasible to ensure the accuracy of the sample. These dilemmas mirror the typical shortcomings that characterize online data collection (Murthy, 2008).

\section{Findings and discussion}

To best explore how gendered identities are constructed and performed, whether subjects have the potential to resist these constructions, and the impact of the online environment on these findings, results and analysis are presented thematically: (1) discourses that constructed gender; (2) the treatment of feminism; (3) the politics of reappropriation; (4) the connection between 'inclusiveness' and intersectionality; and (5) the relationship between CMC and FTF interaction throughout the life cycle of sites. 


\section{Discourses that constructed gender}

The discourses considered to constitute gender were primarily concerned with enabling subjects to avoid being inscribed within undesirable subject positions. This was ensured through the construction of the self in opposition to negative subject positions, allowing this process to be framed as a navigation of disadvantageous subject positions characterized by overt sexualization (which conveyed an aggressive sexuality), and a lack of sexuality (which jeopardized the sexual desirability of the subject). This negotiation process was found to construct subjects' identities relationally in response to a masculine subject, which was defined with reference to RW Connell's (2005) understanding of hegemonic masculinity as the dominant form of masculinity within the gender hierarchy - which is underpinned by a normative ideal of male behaviour. This navigation process was reflected in subjects' engagement with the broad aims of the Slut Walk movement (such as the promotion of consent) in a way that incorporated these aims, exemplified by the statement : 'Real men know that consent is sexy' (Hobart collaborator). This statement defines the speaker in relation to a masculine subject who is vested with the power to deem the author of the comment 'sexy'. It allows the author to avoid presenting an aggressive sexuality by aligning the promotion of consent with the position of a masculine subject.

'Yes, I am a feminist. No, I don't hate men' (Launceston collaborator). These statements once more illustrate an effort to avoid delegation to an undesirable subject position, and the subject is again defined in relation to a masculine subject. Notably, in discursive acts of this nature throughout the network of sites, the masculine subject that gendered identity was constructed relationally in response to was never a single individual. Rather, they were represented only by their gender, and therefore come to collectively represent all men that have the power to regulate the way in which subjects partaking in this identity negotiation process are constructed.

The discourses that constructed gender were found to be enacted through the navigation of undesirable subject positions, prompted by the definition of subjects in response to an unspecified masculine subject collectively representing all men vested with the power to regulate this process. Such findings verified that the subjects could be contextualized within what Butler termed the 'heterosexual matrix', as their relationally defined identities solidified a normative relationship between gender, (hetero)sexuality and desire. Gaining an understanding of this process was crucial, as it allowed for subsequent examination of the potential that subjects had for resistance.

\section{The treatment of feminism in a post-feminist context}

Within the network of sites subjects displayed an ambivalent relationship with the aims of Slut Walk, which was then reflected in their treatment of feminism. Importantly, the Slut Walk movement draws upon various elements of feminist discourses. For example, it parallels with the 'Take Back the Night' rallies which began in 1975 as protests against rape and sexual assault, while its 'sex-positive' and inclusive emphasis references the third-wave feminism of the 1990s. Although (by virtue of its reference to previous movements) Slut Walk is considered to be a feminist movement, there was a lack of 
explicit identification with feminism within the Facebook pages. Instead, feminism was implicitly incorporated into the rhetoric of the movement through statements such as: 'I need feminism because when he called me a slut after sexually assaulting me, I believed him' (Perth mediator). This mirrors the catch cry of 'This is why I need Slut Walk' that echoed throughout the web pages. The prevalence of discourses such as these resulted in the equation of Slut Walk with feminism and the seemingly interchangeable use of both terms.

Nevertheless, the lack of explicit identification with feminism, mixed with rhetorics of 'choice' feminism (an intersection of post-feminism and neoliberalism which emphasizes individuality and one's freedom of choice), within the network of sites made reference to the ambivalence of 'post-feminist' discourses which accept the achievements of feminism, while dismissing its contemporary relevance. By linking Slut Walk with 'postfeminist' discourses the masculine subject in reference to whom the participants established their identities can be understood as McRobbie's hegemonic masculine ideal which forms an essentialized, collective idea of men. 'He' comes to stand for all men who are vested with the power to shape the participation of other (not always female) subjects in the 'post-feminist masquerade'. ' $\mathrm{He}$ ' is defined collectively solely on the basis of gender, which suggests that the identity construction process of the subjects that are defined in response to him is similarly dominated by considerations of gender.

\section{The politics of reappropriation}

By virtue of its name, the Slut Walk movement is inextricably linked to notions of reclamation and reappropriation of discourse. This is best demonstrated through efforts to reappropriate and reclaim the term 'slut'. Such efforts were directly implicated in the dominant construction of gendered identity, which illustrates that it provides a crucial foundation from which to discuss the degree of success achieved by attempts at resistance. These struggles were evident across the Facebook pages and were divided into collective and individual efforts. Analysis focused on the example that was most prevalent throughout the network: the attempt to reappropriate the word 'slut'. The connotations of promiscuity and unrestrained sexuality that surround the term 'slut' characterize one of the subject positions that the 'post-feminist masquerade' was enacted to avoid (that of hyper-sexualization). Therefore, the success of acts of resistance in which 'slut' was deployed can be assessed through Butler's framework. Within this framework a successful act of resistance is one that subverts the norms that solidify the heterosexual matrix. These norms were established within the Facebook pages through subjects' participation in the 'post-feminist masquerade'. Hence, the potential for deployment of a successful act of resistance was located in the use of 'slut' in a way that denaturalized and challenged the dominant way that it was perceived.

Although the collective project of resistance - Slut Walk's effort to reappropriate 'slut' - has garnered attention from both individuals and international media, its subversive potential is diminished when viewed through Butler's framework. This is due to the fact that mass efforts at reappropriation repeated these subversive acts by using 'slut' in identical ways throughout the network, evidenced by the catch cry of 'welcome sluts and allies'. Even if this act was initially destabilizing, its repetition resulted in its 
routinization within the norms solidifying the heterosexual matrix, which stripped it of its subversive potential. This dilemma, coupled with the incompatibility of Butler's work with a comprehensive notion of intersubjective resistance and collective solidarity, demonstrates that mass attempts at resistance enacted in this way were unlikely to successfully subvert the norms that stabilize the heterosexual matrix in the context of the Facebook web pages.

In light of the seeming inability of large-scale collective narratives to affect resistance, this article instead focuses on individual acts of rearticulation (Butler, 1993: 16). Within the Facebook web pages there was evidence of individual attempts to reappropriate discourse through the inventive use of language, such as 'sluttastic', and through ironic reimaginings of incidents of street harassment in which the narrator adopts the label of a 'slut'. Discursive acts of this nature represented a creative ${ }^{10}$ utilization of power that was not yet routinized within the heterosexual matrix, as although 'sluttastic' may superficially be considered a repetition of the term 'slut' (mirroring collective repetition of the term) the unexpected way that it used language suggests that it was momentarily vested with the potential to destabilize the word's meaning due to the fact that it cannot immediately be understood discursively. Therefore, the subversive potential of this act lies in its ability to momentarily destabilize the norms constructing the heterosexual matrix through its denaturalization of the word 'slut', which may force viewers of the site into a moment of reinterpretation. This tenuous moment of subversion mirrors the resistance located by Renold and Ringrose (2008). Building upon their work, we adopt the notion of ruptures to describe the fleeting and transgressive nature of these momentary, individual acts of resistance. As these ruptures of the heterosexual matrix have been located in these individual acts of resistance, their potential impact can now be examined. This is framed, in Butler's (2006: 533) words, as a question of whether they constitute a 'strike or blow' against the heterosexual matrix.

\section{The connection between 'inclusiveness' and intersectionality}

The online manifestation of the Slut Walk movement incorporated bids for mass resistance, enacted through appeals to collective solidarity. This highlighted the necessity of examining the internal cohesion of the sites in order to determine whether they offered the potential for mass solidarity. Although there were widespread appeals for internal cohesion across the network, represented through frequent expressions of support from collaborators such as, 'Thank you Slut Walk organizers, we're all in this together!' (Perth collaborator), there was also evidence of conflict. A possible exacerbating factor was the decentralized nature of the sites, resulting in minimal guidelines dictating how the marches and subsequent groups should operate. The only explicit guideline was the emphasis on inclusiveness throughout the network of pages, following the precedent set by the original Slut Walk Toronto page. This notion of inclusiveness was premised on a desire to accommodate people of all ethno-racial backgrounds, socio-economic positions and sexualities, and appeared to be motivated by the concept of intersectionality which is associated with contemporary manifestations of feminism. Importantly, an intersectional approach to one's identity rejects the notion that gender is the primary criterion upon which feminist approaches should be based, and instead strives to achieve an 
understanding of how facets of one's identity intersect (rather than accumulate) to construct their social positioning(s).

We found that the ability of the online expression of the Slut Walk movement to meet its prescribed aims - the reappropriation of discourse and incorporation of the vaguely stated notion of inclusiveness - was undermined by both a lack of internal cohesion, and a shallow understanding of inclusiveness. For example, gender was positioned as the primary criterion on which inclusion and exclusion were based, as demonstrated by the discussion of whether men had the right to identify as 'sluts', or could only be considered allies, exemplified in statements such as: 'The denial of male victims hurts women too' (Edinburgh collaborator). This presented a call to solidarity. This was mirrored across the network, demonstrated by the binary understanding of men as perpetrators and women as victims that showed gender to be the primary criterion on which commonality was established, informing women's right to self-identify as a 'slut' or an 'ally', while men could only identify as an 'ally'. Debates about whether aspects of subjects' identities impacted upon their right to self-identify as a 'slut' or 'ally' complicated this model.

Within these debates there was evidence of engagement with the notion of accumulated disadvantage, which allowed some men, determined by their level of perceived disadvantage or marginalization, to self-identify as victims, supported by statements such as 'the denial of male victims hurts women too' and 'if you deny the experience of men you're denying the experience of sex workers'. The conflict surrounding such issues was exemplified in discussion on the Slut Walk New York City site, in which the administrator's primary focus on gender meant that they were unable to fully acknowledge racialized experiences - which marginalized facets of subjects' identities aside from gender and highlighted an inability to account for the way that aspects other than gender intersected within subjects' identities. Therefore, despite the emphasis which these sites placed upon inclusiveness, these discussions failed to display an understanding of identities as intersectional.

Indeed, rather than decentring the primary role gender played in determining how subjects could self-identify, it structured various dimensions of subjects' identities into a hierarchy topped by gender. This undermined the network's goal of inclusiveness as it resulted in relational constructions of a self that were reliant on a negative other. Therefore, the relational definition of subjects and prioritization of gender within the network of sites was found to contradict the goals of the Slut Walk movement, damaging its ability to fulfil its own aims.

The frequent inability of both mediators and collaborators to acknowledge the intersecting facets constituting subjects' identities also undermined the subversive potential of acts of resistance, preventing them from effecting ruptures of the heterosexual matrix. Ethno-racial backgrounds were incorporated in the 'post-feminist masquerade' within the network of sites, demonstrated by the simultaneous acceptance and dismissal of notions of multiculturalism and tolerance, effecting a 'double subordination' in which both feminism and multiculturalism were subject to the appropriative relationship characteristic of the network's 'post-feminist' context. This rendered non-white femininities unintelligible by restructuring the boundaries of acceptable femininity, thereby framing ethno-racialized experiences of gender as non-normative. The process of subordination was extended beyond both gender and ethno-racial backgrounds to encompass diverse 
facets of subjects' identities, framing multifaceted identities that challenged the centrality of gender as non-normative gender identities (as they transgressed the aims that motivated engagement with the 'post-feminist masquerade'). In light of this, analysis focused on whether momentary ruptures of the heterosexual matrix located within the Facebook web pages had the power to render these non-normative gender identities intelligible. Acts of reappropriation that expressed non-normative gender identities discursively, and subsequently denaturalized the norms that constructed the subject in a way that rendered the subject intelligible, were therefore located as the acts vested with the power to effect a 'strike or blow' against the heterosexual matrix.

The unsuccessful effort at collective resistance detailed above once again directed consideration to individual modes of resistance. These attempts were more compatible with an intersectional understanding of identity, as they represented diverse individuals rather than collective subjects. Notably, individual acts of resistance in which gender was decentred as the most prominent facet of identity in favour of a more holistic approach to subjects were scattered throughout the network of sites. The most striking examples were testimonials in which subjects expressed that 'I would call myself a slut', within the context of their own personal narratives. Individual identification as a 'slut' differed from the mass identification enacted by the wider movement as these instances were not repetitions, they could not be divorced from their particular meanings and therefore were not at risk of becoming routinized and subsequently incorporated into the norms stabilizing the heterosexual matrix. Within these testimonials the prominence of gender was decentralized, as it could not be understood separately from the facets of subjects' identities that were simultaneously expressed, facilitating acknowledgement of the intersectionality of identity, and allowing for an understanding of constructions of gender that was informed by multiple facets of subjects' identities. This reappropriation therefore accessed the potential outlined above to subvert the norms that stabilize the heterosexual matrix, rendering non-normative (intersectional) gendered identities intelligible. Consequently, it is considered to constitute a 'strike or blow' against the heterosexual matrix.

Importantly, it should be noted that the potential for inclusiveness and an acknowledgement of the intersectionality of identity was constrained by the content of the web pages. Although they represented particular locales they rarely exhibited engagements with the specific challenges which were faced in these locales (with the page of Slut Walk New York City providing a notable exception). Instead, the participants appeared to engage with broad discourses and presented much of the same material on each of their pages, signifying a homogeneous engagement with feminist and 'post-feminist' discourses. It appeared that solidarity across the movement was achieved at the expense of the particularity of experience in each locale.

\section{The relationship between CMC and FTF interaction throughout the life cycle of sites}

Examination of the discursive construction of identity within the Facebook pages highlighted shifts in the use of these pages, illustrated by the fluctuating relationship that these pages had with the specific locale they represented and the specific time-frames which they represented. The sites initially focused on recruiting for the marches that 
constitute the FTF manifestation of the movement, expressed through strong emphasis on the connection between the online and offline elements of the Slut Walk movement. 'Welcome sluts and allies, we'll see you all at the march!' (Melbourne). This comment amply illustrated the temporary use of these sites as spaces for planning and disseminating the details of the marches. In this initial phase the sites were used primarily to provide information about the march and the wider movement. This changed after the march or rally, with these sites most often becoming networks of links to useful online resources which were often not bound to a specific time or place. Although at this point the online manifestation gained primary importance, loose connections to the geographically bound time and space which the sites initially represented remained.

Although the majority of the sites moved between these two forms (dependent on the impending occurrence of a march) the sites of Slut Walk New York City and Slut Walk Singapore/Kuala Lumpur moved onto a third, inactive stage. Although content was no longer contributed, these pages remained part of the network, held in place by their links to other sites, and existing as sites containing useful information. The final two stages which these sites went through appear to have potential implications for how individuals interact with them. For example, while the link between social media use and political engagement has been studied widely, especially in the context of the 2008 US election (see Vitak et al., 2011), more recent scholarship has highlighted that individuals also rely on social media as a source of more general news and information (Zuniga et al., 2012). When this insight is combined with the claim that social media platforms, such as Facebook, allow users to establish pages which function as archives (Good, 2013), it becomes apparent that the network of Slut Walk Facebook pages which were included in this study may be used to provide an archive of useful information to users which is not bound by its original space and time.

The various stages which these sites went through, as well as their fluctuating relationships with time and space, had implications for the processes of identity construction and resistance outlined above. The relevance that ruptures enacted within the Facebook pages could have beyond their immediate context can be explored using Murthy's (2012) adaptation of Goffman's (1959) work. Using Goffman's original concept of 'embedding', referring to the scope for utterances which were removed from their original author to be re-embedded, Murthy developed the concept of 'synthetic embedding' in order to adapt Goffman's work to an online context. Such a process occurred within the Facebook pages explored, illustrated by the way in which utterances in the form of phrases, rhetorics and images came to be repeated throughout the network. The subversive possibilities inherent within this are illustrated by the potential for the ruptures located within the network to be re-embedded within new contexts. As highlighted by Marwick and boyd (2010), participants in mediated interactions have an awareness of an audience, even in a constructed or imaginary form. The implication of this it twofold: first, this awareness helps to shape performances of the self into a form which can be interpreted by other subjects. Second, the presence of an audience illustrates that the impact of ruptures extends beyond their immediate context through being viewed by this audience. This claim suggests that the relationship between ruptures and their online context enhances their subversive potential. By providing the potential for ruptures to be continually re-embedded in new contexts, this context provides them with a longevity 
they may not otherwise achieve. Additionally, this relationship illustrates the fluid connections between online and offline environments by highlighting the potential for mediated performances of the self to impact upon each context.

Importantly, when the web pages went from being spaces for organizing action which would occur in a FTF context to simply providing spaces for interaction, information and connection they appeared to fracture from the FTF expression of the movement. This points to the necessity of tempering the subversive potential of ruptures enacted within the sites with an acknowledgement of their limitations. The distance of these sites from the FTF movement, in turn, impacted upon the ways in which individuals interacted with them. Specifically, while they were connected to the movement many discussions were particular to the locale which the page represented, and then when the web page fractured from the wider movement the discussions largely became more general. This demonstrated that although the online context of these sites presented individuals with a creative and fluid space in which to perform their identities, when these spaces were linked with the FTF expression of the movement such expressions were inevitably constrained by the structural and systemic factors which govern social life. Specifically, due to the neoliberal context in which the locales which were studied can be situated, this manifested as a freedom to express oneself within the bounds of acceptable identities (McRobbie, 2009). Notably, when the web pages ceased to be connected directly with the FTF expression of the movement, they also largely ceased to refer to the specifics of their locale. The way in which the identity process was impacted by its proximity to FTF expressions served to remind us that although the participants engaged in the freeing environment of online interaction, they nevertheless remained situated in the social context of their everyday lives.

\section{Conclusion}

By exploring the ambivalent engagement of feminism through Slut Walk Facebook web pages, we determined that the discourses constitutive of gendered identity were constructed by subjects' participation in the 'post-feminist masquerade'. Through this interpretation, insight was gained into the nature of the identity construction process, which facilitated exploration of the significance of the relational construction of subjects' identities (in response to an unspecified masculine subject). The abstract nature of the masculine subject - framed as a hegemonic masculine ideal - illustrated that subjects were defined relationally on the basis of gender, which explained the prioritization of gender throughout the network. Interpretation of this process allowed for exploration of whether it could be resisted. Butler's work was used to provide the criteria on which the success of resistance efforts was assessed. Such efforts were reframed as attempts to resist the norms which stabilized the heterosexual matrix. This analysis focused on efforts to reclaim and reappropriate 'slut'. Engagement with Butler's conceptual framework diminished the possible success of collective resistance attempts via large-scale efforts at reappropriation, because the frequent repetition of these acts resulted in their incorporation within the norms that solidify the heterosexual matrix. Our analysis was therefore directed towards exploration of the potential for resistance located within individual, momentary acts of resistance (conceptualized as ruptures) of the heterosexual matrix. 
Examples of tension throughout the Facebook web pages in our sample highlighted how the Slut Walk movement's projects of resistance and inclusiveness were undermined by the inability of both collaborators and mediators to acknowledge the intersectionality of subjects' identities. Conflict in this case demonstrated the multidimensional way in which the 'post-feminist masquerade' subordinated subjects, as diffuse facets of their identities were drawn into this process and subsequently, appropriated and dismissed. This process privileged the role of gender, placing it atop a hierarchy of identity, and thus rendered all experiences of gender that were impacted by other facets of subjects' identities as non-normative. Therefore, ruptures found to have the power to effect a 'strike or blow' against the heterosexual matrix were those that enacted reappropriation through the discursive expression of non-normative gendered identities in a way that denaturalized the norms constructing them, thereby rendering them intelligible.

The online context of this study suggests a subversive potential. Since ruptures can be removed from both their author and original context, the potential for application beyond their intended purpose is latent within their creation. Additionally, the existence of an audience, which constitutes an integral facet of Facebook web pages, illustrates the potential for the impact of these ruptures to be maintained in an archival format by the online space's divorce from the immediate impact of time and geographic space, to be extended into online spaces outside the immediate network of sites, and perhaps even into offline spaces.

By exploring the differential levels of success encountered by the processes of identity construction, this study illustrates some ways in which the subversive potential provided by online spaces can be harnessed by the subject. Nevertheless, by highlighting the neoliberal context in which the FTF counterparts of these web pages were situated, we aimed to maintain reference to the structural factors which impacted upon the creative potential of online spaces. Indeed, we found that the pervasiveness of patriarchal and neoliberal forces are no longer expressed through the power of official state channels. Instead, they were perpetuated through the informal channels of culture, as we saw by focusing on the Slut Walk Facebook web pages.

\section{Acknowledgements}

We are grateful to Bernie Hogan, Jennifer Hsu and the three anonymous reviewers for their insightful comments and valuable feedback.

\section{Funding}

This research received no specific grant from any funding agency in the public, commercial, or not-for-profit sectors.

\section{Notes}

1. These terms are contested and present an over-simplification of expressions of feminism. Notwithstanding, the linear model of feminist thought, which they denote, will be used to illustrate the discourses which the Slut Walk movement draws upon.

2. All of the locales examined in this study can be broadly situated in a neoliberal context, as they are increasingly subject to globalization and display the homogenizing trends of 
individualization and instrumental rationality. Therefore, while the development of 'postfeminism' has largely been linked with a North American context, it is nonetheless applicable to the locales which are included in our study.

3. We adopt Rodino's (1997) definition of binary understanding of gender as 'the system which naturalizes patriarchy'.

4. Although Murthy's work focused on social media such as Twitter, the traits of Twitter that were emphasized mirror the key features of the web pages analysed in this study. Specifically, Murthy (2012: 1061) highlights that Twitter is public, interactive, networked, and can be used to multicast.

5. The term 'Wall' here refers to the text component of the Facebook pages in question where content could be read and commented on.

6. The Facebook pages of the Slut Walk movement were publicly accessible, which meant that anyone with a Facebook account could contribute to them. Nevertheless, the administrators of the pages could moderate these contributions.

7. The Occupy movement - a protest against social and economic inequalities started with the 17 September 2011 protest on Wall Street, New York City, and spreading to other locations within and outside the USA - provides an ideal comparison to the Slut Walk movement since it was organized with the aid of Facebook, and utilized online spaces for the secondary purpose of storing and sharing information.

8. Although we examined various local Slut Walk sites around the world, the sample is skewed towards English speakers.

9. The power of the hegemonic masculine ideal resides in its ability to render subjects unintelligible through delegation to undesirable subject positions.

10. Creative in this sense refers to Butler's (1993) interpretation of JL Austin's assertion that some utterances had the power to bring what they spoke of into being, terming them performatives.

\section{References}

Bakardjieva M (2008) Bulgarian online forums as carnival: Popular political forms and new media. In: Sudweeks F and Ess C (eds) Proceedings Cultural Attitudes Towards Communication and Technology. Melbourne: Murdoch, pp. 286-300.

Bechar-Israeli H (1995) From $<$ Bonehead $>$ to $<$ cLoNehEAd $>$ : Nicknames, play, and identity on internet relay chat. Journal of Computer-Mediated Communication 1(2).

Bornstein K (1998) My Gender Workbook. New York: Routledge.

boyd D and Ellison NB (2008) Social network sites: Definition, history, and scholarship. Journal of Computer-Mediated Communication 13(1): 210-230.

Butler J (1990) Gender Trouble. New York: Routledge.

Butler J (1993) Bodies That Matter. New York: Routledge.

Butler J (2006) Responses to special issue: Troubling identities: Reflections on Judith Butler's philosophy for the sociology of education. British Journal of Sociology of Education 27(4): $529-534$.

Butler J (2013) For white girls only? Postfeminism and the politics of inclusion. Feminist Formations 25(1): 35-58.

Connell RW (2005) Masculinities. Berkeley: University of California Press.

Crenshaw K (1994) Mapping the margins: Intersectionality, identity politics, and violence against women of colour. In: Fineman MA and Mykitiuk R (eds) The Public Nature of Private Violence. New York: Routledge.

Danet B (1998) Text as mask: Gender and identity on the internet. In: Jones SG (ed.) Cybersociety 2.0. Thousand Oaks, CA: Sage. 
Fairclough N (2003) Analyzing Discourse: Textual Analysis for Social Research. London: Routledge.

Goffman E (1959) The Presentation of Self in Everyday Life. New York: Doubleday Anchor Books.

Good K (2013) From scrapbook to Facebook: A history of personal media assemblage and archives. New Media and Society 15(4): 557-573.

Herring SC (1993) Gender and democracy in computer-mediated communication. Electronic Journal of Communication 3(2).

Jurgenson N (2012) When atoms meet bits: Social media, the mobile web and augmented revolution. Future Internet 4(1): 83-91.

Knorr Cetina K (2009) The synthetic situation: Interactionism for a global world. Symbolic Interaction 32(1): 61-87.

Kofoed J and Ringrose J (2012) Travelling and sticky affects: Exploring teens and sexualized cyberbullying through a Butlerian-Deleuzian-Guattarian lens. Discourse: Study in the Cultural Politics of Education 33(1): 5-20.

Lloyd M (2007) Judith Butler: From Norms to Politics. Cambridge: Polity.

McRobbie A (2009) The Aftermath of Feminism: Gender, Culture and Social Change. London: Sage.

Marwick AE and boyd D (2010) I tweet honestly, I tweet passionately: Twitter users, context collapse, and the imagined audience. New Media and Society 13(1): 114-133.

Murthy D (2008) Digital ethnography: An examination of the use of new technologies for social research. Sociology 42(5): 837-855.

Murthy D (2012) Towards a sociological understanding of social media: Theorizing Twitter. Sociology 46(6): 1059-1073.

Niederer S and Van Dijck J (2010) Wisdom of the crowd or technicity of content? Wikipedia as a sociotechnical system. New Media and Society 12(8): 1368-1387.

Reid E (1993) Electronic chat: Social issues on internet relay chat. Media Information Australia 67(1): $62-70$.

Renold E and Ringrose J (2008) Regulation and rupture: Mapping tween and teenage girls' resistance to the heterosexual matrix. Feminist Theory 9(3): 313-338.

Renold E and Ringrose J (2012) Slut-shaming, girl power and 'sexualization': Thinking through the politics of the international Slut Walks with teen girls. Gender and Education 24(3): 333-343.

Ringrose J and Barajas KE (2011) Gendered risks and opportunities? Exploring teen girls' digitized sexual identities in post-feminist media contexts. International Journal of Media and Cultural Politics 7(2): 121-138.

Rodino M (1997) Breaking out of binaries: Reconceptualizing gender and its relationship to language in computer-mediated communication. Journal of Computer-Mediated Communication $3(3)$.

Savage E (2011) Politics of Slut Walk. Eureka Street 21(10): 29-30.

Selfe CL and Meyer PR (1991) Testing claims for online conferences. Written Communications 8(2): 163-192.

Vitak J, Zube P, Smock A et al. (2011) It's complicated: Facebook users' political participation in the 2008 election. CyberPsychology, Behavior and Social Networking 14(3): $107-114$.

Zuniga HG, Jung N and Valenzuela S (2012) Social media use for news and individuals' social capital, civic engagement, and political participation. Journal of Computer-Mediated Communication 17(3): 319-336. 


\section{Author biographies}

Julia Cook is a PhD candidate in the School of Social and Political Sciences at the University of Melbourne. Her research interests include the sociology of youth, time and social movements. Her current work evaluates how young people conceive of distant future horizons by mapping their perspectives onto currents of macro-social change.

Reza Hasmath is a lecturer in the School of Interdisciplinary Area Studies at the University of Oxford.

\section{Résumé}

Cet article examine la construction et la représentation d'une identité sexuée à partir d'une sous-section des pages Facebook du mouvement SlutWalk (Marche des Salopes). Notre analyse suggère que ce rôle sexuel se construit par la participation des sujets à une mascarade post-féministe permettant de définir leur identité sexuée par rapport à l'idéal hégémonique masculin. Cette proposition situe ces pages web dans un espace caractérisé par un traitement ambivalent et approprié du féminisme et, au-delà, au cœur de fortes tensions entre discours féministes et post-féministes. Les actes de résistance sont appréhendés comme des ruptures individuelles et momentanées de la matrice hétérosexuelle de Judith Butler de “l'intelligibilité culturelle”. Le contexte en ligne de ces ruptures est investi par un potentiel créatif qui, en supprimant les contraintes de temps et de lieux, indique que l'impact de ces ruptures peut s'étendre au-delà de leur environnement immédiat.

\section{Mots-clés}

Identité sexuée, féminisme, Slut Walk (Marche des Salopes), médias sociaux, Facebook, résistance

\section{Resumen}

Este artículo analiza la construcción y la performance de la identidad de género a través de una sub-sección de Facebook perteneciente al movimiento Marcha de las Putas. Nuestro análisis sugiere que el género se construye a través de la participación de los en la "mascarada post-feminista "a través del cual su identidad de género se define en relación con un ideal masculino hegemónico. Esto sitúa a las páginas web en un espacio caracterizado por el tratamiento ambivalente y apropiativo del feminismo y, además, enredado dentro de una aguda tensión entre discursos feministas y post-feministas. Los actos de resistencia son encuadrados como rupturas individuales momentáneas de la matriz heterosexual de Judith Butler de 'la inteligibilidad cultural'. El contexto on-line de estas rupturas se encuentra para conferir un potencial creativo, mediante la eliminación de las restricciones de tiempo y lugar, lo que indica que el impacto de estas rupturas pueden extenderse más allá de su entorno inmediato.

\section{Palabras clave}

Identidad de género, feminismo, marcha de las putas, redes sociales, Facebook, resistencia 